\title{
Correction: Specific driving of the suicide $E$ gene by the CEA promoter enhances the effects of paclitaxel in lung cancer
}

Ana Rosa Rama Ballesteros (10 - Rosa Hernández - Gloria Perazzoli • Laura Cabeza • Consolación Melguizo • Celia Vélez · Jose Prados

Published online: 6 February 2020

(c) The Author(s), under exclusive licence to Springer Nature America, Inc. 2020

\section{Correction to: Cancer Gene Therapy}

https://doi.org/10.1038/s41417-019-0137-3

published online 24 September 2019

The original version of this Article contained an error in the spelling of the author Ana Rosa Rama Ballesteros, which was incorrectly given as Ana Rosa Rama. This has now been corrected in both the PDF and HTML versions of the Article. 